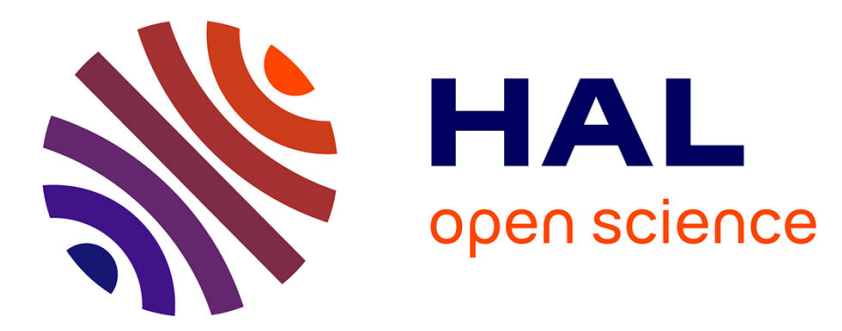

\title{
'They Cooperate With Us, So They Are Like Me': Perceived Intergroup Relationship Moderates Projection from Self to Outgroups
}

\author{
Michael Riketta, Claudia A. Sacramento
}

\section{- To cite this version:}

Michael Riketta, Claudia A. Sacramento. 'They Cooperate With Us, So They Are Like Me': Perceived Intergroup Relationship Moderates Projection from Self to Outgroups. Group Processes and Intergroup Relations, 2008, 11 (1), pp.115-131. 10.1177/1368430207084849 . hal-00571679

\author{
HAL Id: hal-00571679 \\ https://hal.science/hal-00571679
}

Submitted on 1 Mar 2011

HAL is a multi-disciplinary open access archive for the deposit and dissemination of scientific research documents, whether they are published or not. The documents may come from teaching and research institutions in France or abroad, or from public or private research centers.
L'archive ouverte pluridisciplinaire HAL, est destinée au dépôt et à la diffusion de documents scientifiques de niveau recherche, publiés ou non, émanant des établissements d'enseignement et de recherche français ou étrangers, des laboratoires publics ou privés. 


\title{
'They Cooperate With Us, So They Are Like Me': Perceived Intergroup Relationship Moderates Projection from Self to Outgroups
}

\author{
Michael Riketta and Claudia A. Sacramento \\ Aston University
}

\begin{abstract}
Whereas projection of self-attributes to ingroups is ubiquitous, projection of self-attributes to outgroups (outgroup projection) is an elusive phenomenon. Two experiments examined the moderating effect of perceived intergroup relationship on outgroup projection and explored underlying mechanisms. Perceived cooperation versus competition between ingroup and outgroup was manipulated using fictitious (Experiment 1) or natural groups (Experiment 2). In both experiments, participants judged the outgroup as more similar to the self in the cooperation condition than in the competition condition. This effect was independent of recategorization, perceived intergroup similarity, and ingroup-to-outgroup projection. These studies demonstrate the very existence of outgroup projection and extend previous work on moderators of projection from self to groups.
\end{abstract}

KEYWORDS common ingroup identity, intergroup conflict, multilevel analysis, social categorization, social identification, social projection

WHERE DO people's beliefs about social groups come from? Two plausible answers are that (a) people derive their beliefs about a group from their experience with members of that group or (b) adopt a socially shared stereotype of that group. However, research has shown that people form beliefs even about artificial groups, with which they are not familiar and for which no stereotypes exist (e.g. Cadinu \& Rothbart, 1996; Clement \& Krueger, 2002; Gramzow, Gaertner, \& Sedikides, 2001; Otten, 2002). Thus, there must be another mechanism accounting for the emergence of group-related beliefs.

This paper deals with one of these mechanisms: social projection. Several studies have shown that this process accounts for the formation of beliefs about unfamiliar groups (see Otten, 2002). This has been found mainly for ingroups. Projection to outgroups is a more elusive and enigmatic phenomenon. This paper tries to shed light on this process. Specifically, we test the hypothesis that outgroup projection depends

\footnotetext{
Author's note

Address correspondence to Michael Riketta, Work and Organisational Psychology Group, Aston Business School, Aston University, Birmingham, B4 7ET, UK [email:m.riketta@aston.ac.uk]
} 
on the perceived intergroup relationship such that it (a) is strongest among people perceiving harmony (or cooperation) between ingroup and outgroup and (b) is weaker, or even turns into a contrast effect, among people perceiving conflict (or competition) between ingroup and outgroup.

We extend prior research in two respects. First, this is the first experimental test of the mentioned hypothesis, with the goal to demonstrate that perceived intergroup relationship influences outgroup projection (see Riketta, 2005, for correlational evidence). Second, we test whether projection from the self to the outgroup is a direct effect rather than being mediated by perceptions of the ingroup. The former possibility is suggested by cognitive consistency theories (e.g. Greenwald et al., 2002) whereas the latter possibility follows from both the selfanchoring/differentiation model (Cadinu \& Rothbart, 1996) and research on common ingroup identity (Gaertner, Dovidio, Anastasio, Bachman, \& Rust, 1993; see also Robbins \& Krueger, 2005). Moreover, we test whether it is really perceived intergroup cooperation versus conflict, rather than intergroup similarity (Ames, 2004a,b), that drives the postulated effect. The next section develops the research questions in detail.

\section{Social projection and the postulated role of perceived intergroup relationship}

Social projection (also called self-anchoring, Cadinu \& Rothbart, 1996) is the process by which people project attributes that they ascribe to themselves to others (Katz \& Allport, 1931; Krueger, 1998). Several experiments have demonstrated this effect in novel intergroup situations, showing that people spontaneously ascribe their self-perceived traits to minimal groups in the laboratory (e.g. Cadinu \& Rothbart, 1996; Clement \& Krueger, 2002; Gramzow et al., 2001; Otten, 2002). Further, many studies, including research on the false-consensus effect, have found a substantial overlap between attributes (e.g. attitudes, traits) ascribed to the self and attributes ascribed to natural groups (for reviews, see Krueger, 1998, 2000; Mullen et al., 1985; for more recent research, see, e.g. Ames, 2004a,b; Clement \& Krueger, 2002; Jones, 2004; Riketta, 2005). Thus, social projection seems to be common (Krueger, 1998, 2000).

Nonetheless, this process has boundary conditions. A common finding is that people project to ingroups but not (significantly) to outgroups (e.g. Gramzow et al., 2001; Clement \& Krueger, 2002; Krueger \& Zeiger, 1993; Smith \& Henry, 1996; for reviews, see Krueger, 1998, 2000; Otten, 2002). A recent meta-analysis of 48 studies has found an average correlation between selfand ingroup images of $r=.46$, which suggests strong projection, and an average correlation between self- and outgroup images of $r=.13$, which suggests weak projection (Robbins \& Krueger, 2005).

This weak evidence of outgroup projection may appear disappointing considering that several theories and models, such as cognitive consistency theories (Greenwald et al., 2002; Heider, 1958) and the self-anchoring/differentiation model (Cadinu \& Rothbart, 1996), do predict outgroup projection (for a discussion of the relevance of these and other models, see Riketta, 2005, 2006). At the same time, as explained below, these theories and models point to one boundary condition of this effect-the nature of the relationship between ingroup and outgroup. More specifically, these theoretical approaches converge on the prediction that (a) people will project to outgroups particularly if there is cooperation, or harmony, between ingroup and outgroup and (b) will show less projection, or even a contrast effect (i.e. the tendency to ascribe the opposites of self-attributes to outgroups), if there is competition, or conflict, between ingroup and outgroup (see Riketta, 2005). This is the main hypothesis of our research. In addition, we explore several mechanisms that may underlie this effect (ingroup-outgroup projection, recategorization, and perceived intergroup similarity).

\section{The case for direct projection from self to outgroup}

To begin with, the mentioned role of perceived intergroup relationship in outgroup projection 
follows from theories of cognitive consistency, above all from Heider's (1958) balance theory and Greenwald et al.'s (2002) modification of this theory (see also Sherman, Chassin, Clark, \& Agostinelli, 1984). This approach portrays projection from the self to groups as a consequence of the need for cognitive consistency. According to Greenwald et al., once people have formed a positive or 'compatibility' association between cognitive representations of the self and a group (e.g. because they have become members of the group), they tend to form positive or 'compatibility' associations between that group and the attributes they associate with the self. A group image similar to the self-image results; that is, positive projection occurs. Conversely, once people have formed negative or 'incompatibility' associations between self and a group (e.g. certain outgroups), they tend to disassociate that group from the attributes they associate with the self. As a consequence, a group image

(A) Main hypothesis

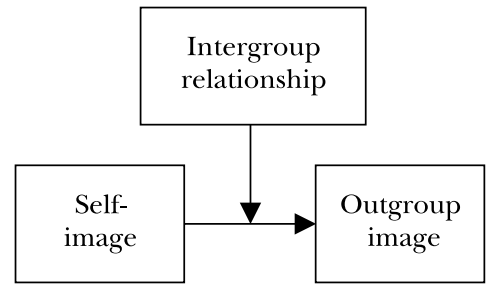

(C) Role of common ingroup identity

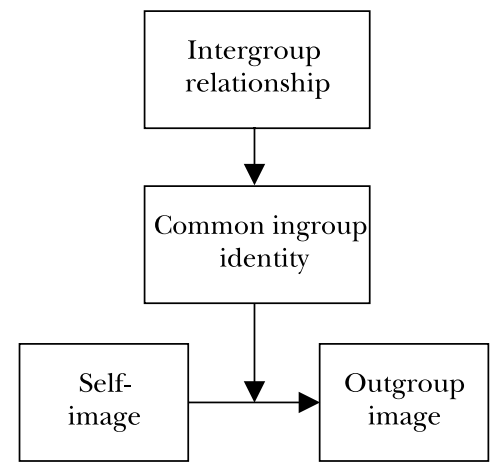

Figure 1. Research questions arises that is dissimilar to the self-image; that is, negative projection occurs. Perceived intergroup cooperation (vs. competition) may be one cause of compatibility (vs. incompatibility) associations between self and an outgroup. Thus, perceived intergroup relationship may determine whether people project onto the outgroup or contrast it away from the self, and how strong either process is. This is our main hypothesis (Figure 1, panel A).

\section{The ingroup image as a mediator of outgroup projection}

The self-anchoring/differentiation model (Cadinu \& Rothbart, 1996) portrays projection as the result of a heuristic by which people make sense of novel intergroup situations. The model postulates a two-step sequence. At first, people project from their self to the ingroup (self-anchoring). Next, they contrast the outgroup away from the ingroup (differentiation).

(B) Role of ingroup image



(D) Role of intergroup similarity

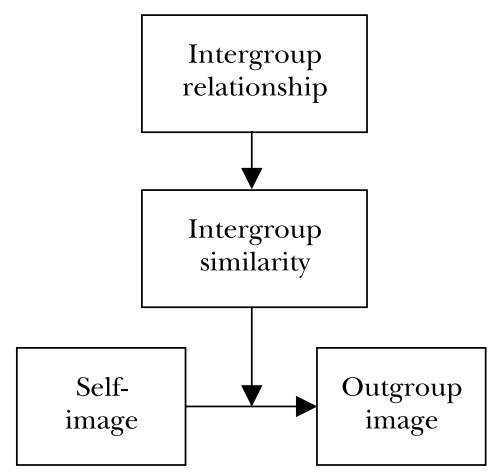


The latter process results in dissimilarity of self- and outgroup image. Thus, according to this model, outgroup projection is negative by default and indirect (i.e. mediated by the ingroup image) rather than direct. Although the model does not refer to the role of perceived intergroup relationship, one may speculate that perceived intergroup relationship (cooperation vs. competition) reduces the tendency to differentiate between in- and outgroup and might even turn it into a tendency to assimilate. By contrast, self-anchoring (projection from self to ingroup) may be independent of perceived intergroup relationship, given the consistency with which this effect has been demonstrated in previous research across a variety of intergroup situations.

Thus, similar to the cognitive consistency approach, the self-anchoring/differentiation model suggests that perceived intergroup harmony versus conflict makes outgroup projection more positive. In contrast to that approach, the selfanchoring/differentiation model suggests that this effect pertains to indirect, not direct, outgroup projection. Specifically, the model suggests that people project from self to ingroup in the first step and that intergroup relationship moderates the subsequent projection from ingroup to outgroup (Figure 1, panel B). The present studies test this prediction and pit it against the alternative hypothesis that perceived intergroup relationship affects direct projection from self to outgroup (independently of ingroup image).

\section{Common ingroup identity as mediator of outgroup projection}

Another explanation for effects of intergroup relationship on outgroup projection is that cooperation between ingroup and outgroup may promote the recategorization of ingroup and outgroup as a single group (Gaertner et al., 1993; Pettigrew, 1998). After this recategorization, projection to the previous outgroup may result from projection to the more inclusive ingroup, which now encompasses the outgroup. In this case, the outgroup would be perceived as similar to the self because it is perceived as part of an ingroup to which people project. This in turn would increase the similarity between self- and outgroup image (for this argument, see Robbins \& Krueger, 2005). Like the self-anchoring/differentiation model, this explanation suggests that outgroup projection is indirect (i.e. mediated by projection to an overarching ingroup) and that perceived intergroup relationship affects only this indirect outgroup projection. This argument extends the self-anchoring/differentiation model by assuming that the described process is accompanied, and facilitated, by the perception of ingroup and outgroup as belonging to the same groupthat is, by a sense of common ingroup identity (cf. Gaertner et al., 1993). Thus, common ingroup identity should moderate outgroup projection and explain the effects of perceived intergroup relationship on projection (Figure 1, panel C; a case of mediated moderation, Baron \& Kenny, 1986; Muller, Judd, \& Yzerbyt, 2005). This possibility is also tested here.

To summarize, our main goal is to test the common prediction of these approaches that perceived intergroup relationship (competition versus cooperation) strengthens outgroup projection. Our second goal is to explore whether the manipulation affects the direct versus indirect (ingroup-mediated) projection to the outgroup. A third, and related, goal is to explore whether the effects of the manipulation are due to common ingroup identity.

\section{Previous findings on the role of perceived intergroup relationship in outgroup projection}

Only one previous study addressed the moderating role of perceived intergroup relationship in outgroup projection (Riketta, 2005). Student participants rated themselves, an ingroup (students of their own major), and an outgroup (business administration students), on identical trait lists and indicated how much conflict between the two groups they perceived. The intraindividual correlations between the trait rating profiles were the indicators of projection. As predicted, the self-outgroup correlation was negative under perceived high intergroup conflict and positive under perceived low intergroup conflict, especially when identification was high. 
These findings tentatively suggest that perceived intergroup relationship moderates the direction of outgroup projection. However, the correlational design leaves open questions of causality-in particular, whether (a) perceived intergroup conflict causes negative social projection rather than vice versa and (b) projection is from self to groups rather than vice versa. Further, this previous study did not disentangle direct and indirect projection.

Two other lines of research on social projection dealt with constructs that are related to (yet distinct from) perceived intergroup relationship (Ames, 2004a,b; Jones, 2004). Ames postulated and found in experimental and correlational studies that perceived global similarity of self to in- and outgroups leads to stronger perceived similarity between self and these groups on habits and attitudes. Jones postulated and found in a correlational study that perceived social distance (i.e. average similarity as well as frequency and quality of contact) between self and several in- and outgroups correlated negatively with the magnitude of false consensus on abilities and opinions referring to these groups. Moreover, Jones showed that perceived social distance accounted for the observed stronger false consensus with ingroups relative to outgroups.

These findings are compatible with the present reasoning because perceived intergroup relationship (cooperation vs. competition), the crucial variable in the present research, may be either a cause or a consequence of perceived general similarity and perceived social distance (between self and/or ingroup on the one hand and outgroup on the other). Yet, cooperation versus competition is not the same as similarity or social distance. Research has shown that interpersonal or intergroup similarity and contact (as one component of social distance) can both increase and decrease intergroup conflict (see Hewstone, Rubin, \& Willis, 2002; Pettigrew, 1998). In particular, competition, as a common form of conflict, arises when interdependent groups pursue incompatible goals (Sherif, Harvey, White, Hood, \& Sherif, 1961; Kelley \& Thibaut, 1978). Thus, competition may arise precisely because groups are similar in a certain respect (i.e. in terms of their goals). Further, competition may be stronger under low social distance; that is, if the groups act in the same situation and have frequent contact with each other, provided that the situation is such that each group can reach their goal only at the expense of the other group. Thus, by looking at the competitive versus cooperative nature of the intergroup relationship, the present research looks at a moderator of projection that is conceptually distinct from the moderators examined in Ames' and Jones' studies. Another difference is that whereas Ames and Jones looked primarily at the relationship between self and another person or group as a moderator, the present research examines the relationship between ingroup and outgroup as moderator.

To bolster these arguments with some data, we measured perceived intergroup similarity in Experiment 2 (see below) and tested whether this variable explained the effects of manipulated intergroup relationship on outgroup projection (Figure. 1, panel D; another case of mediated moderation). To anticipate, our results show that the effects of intergroup relationship are independent of perceived intergroup similarity. Thus, the present research extends previous work on similarity as a moderator of projection.

\section{Overview of the current research}

We report two studies in which we manipulated the perceived relationship (cooperation vs. competition) between an ingroup and an outgroup. We tested whether outgroup projection was stronger under cooperation than competition. To shed light on the nature of outgroup projection, we tested three mechanisms of outgroup projection (ingroupoutgroup projection, Experiments 1 and 2; recategorization, Experiment. 2; intergroup similarity, Experiment. 2).

Our studies are unique in several respects. First, they are the first to test the causal role of perceived intergroup relationship in outgroup projection. In this respect, they extend previous correlational findings on the relations between perceived intergroup relationship, self-image, and outgroup image (Riketta, 2005). Second, the present studies are the first to distinguish between direct and indirect (i.e. ingroup mediated) 
outgroup projection in testing for moderators of this process. As a consequence, these studies are the first to test whether direct outgroup projection occurs at all. Several researchers questioned the existence of this process, arguing that similarity between the self- and the outgroup image results from indirect projection or is even spurious (e.g. Cadinu \& Rothbart, 1996; Robbins \& Krueger, 2005). By contrast, from the perspective of cognitive consistency theories (e.g. Greenwald et al., 2002), people may project from self to outgroup directly.

Experiment 1 referred to a hypothetical and novel intergroup situation (workgroups in a business scenario). To explore the generalizability of the findings to real-life situations, Experiment 2 referred to groups that were natural and familiar to participants (psychology departments at two universities). Like in previous research (e.g. Ames, 2004a,b; Clement \& Krueger, 2002; Otten \& Wentura, 2001; Riketta, 2005), the direction (positive vs. negative) and strength of projection was assessed with the correlation between self- and group ratings across identical sets of attributes. Positive (negative) correlations indicate positive (negative) projection from self to group. Extending previous research, we used a more advanced method (multilevel modeling) to gauge these correlations. In operational terms, then, our main prediction is that the correlation between self-and outgroup ratings across attributes (as indicator of outgroup projection) is more positive under intergroup cooperation than competition.

We also computed the correlation between selfand ingroup ratings as an indicator of projection from self to ingroup. This process is implied in the ingroup-mediation model (Figure 1, panel B). Because ingroup projection has been demonstrated many times (e.g. Robbins \& Krueger, 2005), a positive correlation has to be expected.

One challenge with our operationalization of projection is to ensure that the correlation between self- and group ratings actually reflect the projection of single attributes and are not due to general evaluative tendencies. For example, if participants have a general tendency to evaluate both the self and the outgroup positively (i.e. tend to give higher ratings on positive than negative attributes for both self and outgroup), a positive correlation between trait ratings of selfand outgroup would result, even in the complete absence of projection (for this argument, see Otten \& Wentura, 2001; Sherman et al., 1984). To control for this possibility, following Otten and Wentura (2001) and Riketta (2005), we controlled for the valence of the single attributes in computing the correlations between self- and group ratings. For exploratory purposes, we repeated all analyses described in the following without valence as control variable. The results are similar (see Appendix B for the full results). In the text, we discuss only the results with valence as control variable.

\section{Experiment 1}

\section{Method}

Sample and procedure Forty-nine students (21 male, 28 female) at the University of Tübingen, Germany, participated in exchange for sweets. They were recruited on a voluntary basis in a student dining hall and completed a questionnaire in a remote area of the hall.

Materials On the first page of the questionnaire, participants judged themselves on 17 adjective pairs, each of which was separated by a 7-point rating scale. The adjective pairs were selected to cover a broad range of personality attributes, which were semantically unrelated to the conflict-cooperation dimension (see Appendix A).

On the next page, participants read a scenario adapted from Alexander, Brewer, and Herrmann (1999, Study 2, conditions 'ally' and 'enemy'). The scenario described two work teams (Team A and Team Z) in a retailing organization that distributed lawnmowers. Participants were instructed to imagine that they were the leader of Team A. Both teams were described as similar in terms of size, market share, and competence of the team members. Participants read that the top management of the organization had offered a trip to the Caribbean Sea to the team that sold more than 10,000 lawnmowers over the next 12 months. The perceived intergroup 
relationship was manipulated in the last passage of the scenario. In the competition condition, it read: 'Only one of the two teams can win the trip, namely the team that will be the first one to sell 10,000 lawnmowers over the next 12 months. If Team $\mathrm{Z}$ is the first to reach this quota, it will win the trip, and your team will get nothing'. In the cooperation condition, the passage read: 'It is possible that both your team and Team $\mathrm{Z}$ will sell over 10,000 lawnmowers. In this case, each team will win the trip. If Team A and Team $\mathrm{Z}$ cooperate and share markets, this will help them to reach the 10,000 quota each and to win the trip jointly'. Participants were randomly assigned to the conflict or cooperation condition.

On the next page, participants read that the goal of the study was to explore processes of spontaneous impression formation. They were asked to indicate their spontaneous and intuitive impressions of the outgroup (Team Z) and the ingroup (Team A). Each group had to be judged on a list of adjective pairs that was identical to that used for the self. Because the main focus of this study was on projection to the outgroup (not on the ingroup), the outgroup ratings were always measured before the ingroup ratings.

Next, as a manipulation check, participants judged the perceived relationship between Team A and Team Z. The items (adapted from Riketta, 2005) were: 'I think that in general, the members of Team A and Team Z easily get to like each other' (reversed), 'I think the members of Team A and Team $\mathrm{Z}$ easily get to dislike each other', 'I think the relationship between the members of Team A and Team Z is harmonious' (reversed), and 'Team A and Team Z compete with each other'. Each item was accompanied by a 7-point scale anchored with not applicable at all and totally applicable. Responses were averaged $($ alpha $=.84)$.

Multilevel modeling In this and the following study, the data were analyzed with multilevel modeling. This is the most appropriate method to analyze nested data (Raudenbush \& Bryk, 2002). In our studies, ratings of single attributes were nested within participants. In the terminology of multilevel modeling, the attribute ratings were variables at level 1 , and participants were at (the hierarchically higher) level 2.

Test of the main hypothesis In the tests of the main hypothesis (i.e. that conflict affects outgroup projection across attributes and participants), outgroup ratings was the criterion variable and self-ratings and the valence of each rated attribute (as control variable) were the predictor variables. Like in previous research (Riketta, 2005; also Otten \& Wentura, 2001), valence was coded positive or negative on the basis of German word norms (Hager \& Hasselhorn, 1994, Table 4-3).

To test for the moderating effect of conflict on outgroup projection, we used a random coefficients model (Raudenbush \& Bryk, 2002). Experimental condition (competition vs. cooperation) was included as a moderator variable at level 2. In general, a random coefficients model estimates a single regression equation (here: regression of outgroup rating on selfrating) across all level 1 data points (here: attributes) but allows the intercept and slope of this regression to vary across level 2 data points (here: participants). In terms of this model, our hypothesis predicts that the variation of the slopes (i.e. the relationship between self- and outgroup ratings) is due to a level 2 variable (here: condition) or, in another words, that there is a cross-level interaction between self-ratings and experimental condition. To test this, we estimated the following model, following the common procedure of testing cross-level interactions (e.g. Hofmann \& Gavin, 1998):

$$
\begin{aligned}
& \text { Level-1 Model } \\
& \text { Outgroup ratings }=\mathrm{P} 0+\mathrm{P} 1 *(\text { self-ratings }) \\
& +\mathrm{P} 2 *(\text { attribute valence })+\mathrm{E} \\
& \text { Level-2 Model } \\
& \mathrm{P} 0=\mathrm{B} 00+\mathrm{B} 01 *(\text { condition })+\mathrm{R} 0 \\
& \mathrm{P} 1=\mathrm{B} 10+\mathrm{B} 11^{*}(\text { condition })+\mathrm{R} 1 \\
& \mathrm{P} 2=\mathrm{B} 20+\mathrm{R} 2
\end{aligned}
$$

with P0, B00, B10, B20: intercepts; P1, P2, B01, $\mathrm{B} 11$ : regression weights; and $\mathrm{E}, \mathrm{R} 0, \mathrm{R} 1, \mathrm{R} 2$ : residuals; condition coded 0 for cooperation and 1 for competition; attribute valence coded 0 
for negative and 1 for positive. The intercepts and regression weights can be interpreted like intercepts and regression weights from ordinary least-squares regression analyses.

The crucial parameter for present purposes is B11. It denotes the extent to which projection (i.e. P1) varies as a function of experimental condition. A negative value of B11 would indicate that, as expected, the relation between self- and outgroup ratings is less positive (or more negative) under competition than under cooperation.

Test for the role of ingroup image in outgroup projection In additional analyses, we tested for the prediction by the self-anchoring/differentiation model that the effect of the experimental manipulation pertained to projection from ingroup to outgroup (assuming that participants projected from self to ingroup at first) rather than to direct projection from self to outgroup. To test this, building on the logic of regression-analytic mediation analysis (Baron \& Kenny, 1986), we entered ingroup ratings as an additional predictor and tested for the effects of experimental condition on the effects of self- and ingroup ratings simultaneously. To the extent that the effects of condition on the selfoutgroup relation were weaker in this than in the aforementioned analysis, this would suggest that the manipulation affected projection from ingroup to outgroup rather than from self to outgroup. Conversely, if the self-outgroup relation were the same in this analysis, this would suggest that the manipulation affected direct projection from self to outgroup. Specifically, in these analyses, we estimated the following model:

\section{Level-1 Model}

Outgroup ratings $=\mathrm{P} 0+\mathrm{P} 1 *$ (self-ratings $)+$ $\mathrm{P} 2 *$ (ingroup ratings) $+\mathrm{P} 3 *$ (attribute valence) $+\mathrm{E}$

Level-2 Model

$$
\begin{aligned}
& \mathrm{P} 0=\mathrm{B} 00+\mathrm{B} 01 *(\text { condition })+\mathrm{R} 0 \\
& \mathrm{P} 1=\mathrm{B} 10+\mathrm{B} 11^{*}(\text { condition })+\mathrm{R} 1 \\
& \mathrm{P} 2=\mathrm{B} 20+\mathrm{B} 21 *(\text { condition })+\mathrm{R} 2 \\
& \mathrm{P} 3=\mathrm{B} 30+\mathrm{R} 3
\end{aligned}
$$

with P0, B00, B10, B20, B30: intercepts; P1, P2, P3, B01, B11, B21: regression weights; and E, R0, R1, R2, R3: residuals.

Test for ingroup projection Precondition for a mediating role of ingroup ratings (Figure 1, panel B) is that self-ratings affect ingroup ratings, that is, that projection from self to ingroup occurs (ingroup projection). We tested for this process with a multilevel analysis analogous to the one used to test the main hypotheses, with outgroup ratings replaced by ingroup ratings. To assess ingroup projection independent of condition at first (because we assumed it to be independent of perceived intergroup relationship, see Figure 1, panel B), we conducted this analysis without condition in the equation. To explore whether conflict moderated ingroup projection (an unpredicted effect), we entered condition in the next step.

In all multilevel analyses, we centered the Level 1 predictors (self-ratings, ingroup ratings, and attribute valence) at their means within each participant, following the recommendations of Hofmann and Gavin (1998). All computations were done with HLM 6.0 (Raudenbush, Bryk, \& Congdon, 2004). In the Results section, for sake of brevity, we report only those parameters (B11 and B21) that are relevant to our hypothesis. The complete estimated models are reported in Appendix B.

\section{Results and discussion}

The manipulation check revealed that participants perceived more intergroup conflict in the competition condition $(n=24)$ than cooperation condition $(n=25) \quad(M=5.28$ and 3.82 , respectively; $t(47)=4.70, p<.001$; scale range $1-7)$. We analyzed the effects of the manipulation on projection with multilevel modeling, as described above. As predicted, the relationship between self- and outgroup ratings (selfoutgroup projection) depended negatively on the competition manipulation $(B=-0.09$, $S E=0.02, p<.0001)$. Figure 2 illustrates the effects (following the logic of simple-slope analyses; Aiken \& West, 1991). The effect of selfratings was more positive under cooperation $(B=0.39$, standardized coefficient $=.44)$ than 



Figure 2. Relation between self-ratings (x axis, centered) and outgroup ratings (y axis) by experimental condition, with attribute valence held constant at its theoretical mean (i.e. assuming neutral valence)

under competition $(B=0.30$, standardized coefficient $=.33$ ). Thus, positive outgroup projection occurred in both conditions but was more pronounced in the cooperation condition.

To explore whether the effects of the manipulation were mediated by the ingroup image (i.e. whether perceived intergroup relationship affected projection from ingroup to outgroup rather than from self to outgroup), we entered ingroup ratings as an additional predictor in the analyses and tested the effects of the manipulation on both the ingroup-outgroup and self-outgroup relations, as described in the Method section. Competition versus cooperation had a significantly negative effect on the ingroup-outgroup relation $(B=-0.08, S E=0.03$, $p=.02)$, suggesting that perceived intergroup relationship did affect projection from ingroup to outgroup. At the same time, the effect of the manipulation on the self-outgroup relation was still significant $(B=-0.04, S E=0.02, p=.05)$. Thus, conflict moderated both self-outgroup and ingroup-outgroup projection, but the latter accounted only partly for the effect of conflict on self-outgroup projection.

To test for self-ingroup projection, we conducted an additional multilevel analysis, with ingroup ratings as criterion and self-ratings as predictor (with valence controlled). A significant effect emerged $(B=0.19, S E=0.04, p<.0001$, standardized coefficient .19), suggesting that ingroup projection did occur. When conflict was entered in the equation, it did not significantly moderate ingroup projection $(B=-0.05, S E=0.03, p=.09)$. Thus, in contrast to outgroup projection, ingroup projection was not significantly influenced by perceived intergroup relationship.

Together, these results suggest that participants projected to the outgroup partly via the ingroup, and that the projection from ingroup to outgroup in this sequence depended on perceived intergroup relationship (Figure 1, panel B). This is consistent with the self-anchoring/differentiation model. Still, this effect could not entirely explain the overall effect of the manipulation on self-outgroup projection. Thus, direct projection from self to outgroup was also evident, and the manipulation affected this direct projection as well. The theories reviewed above cannot account for the finding that the self-outgroup projection was positive in the competition condition. The reviewed theories would suggest a negative correlation. A post hoc explanation is that (a) participants tended to ascribe some attributes to all people to some extent, resulting in similar ratings for self and outgroup, and (b) the competition versus 
cooperation manipulation in this study was too weak to override this effect. Because the positive correlation under competition was not replicated in Experiment 1, we will not offer a more detailed interpretation here.

\section{Experiment 2}

One goal of Experiment 2 was to replicate Experiment 1 with natural groups. Another goal was to test whether common ingroup identity and perceived intergroup similarity mediated the effects of the manipulation on outgroup projection. As a further amendment to Experiment 1, we controlled for idiosyncratic ratings of attribute valence.

\section{Method}

Sample and procedure Participants were 150 psychology students at the Faculty of Psychology and Education Science, University of Lisbon, Portugal. Hereafter, this faculty is referred to as FPCE-UL. One professor at this faculty agreed to have the questionnaires distributed to his students at the beginning of his classes. Students were informed that participation was voluntary and were asked to fill in the questionnaires in the classroom straight away. Students received sweets in exchange for participation.

Data from 20 participants had to be excluded from the analysis because they failed to provide any outgroup ratings (3) or attribute-valence ratings (1) or answered the manipulation check incorrectly ( 10 in the competition condition, 6 in the cooperation condition). Of the 130 remaining participants (mean age 21.87 years, $88 \%$ female), 60 were in the competition condition and 70 were in the cooperation condition.

Materials At first, participants judged themselves on 16 attributes. To explore the generality of the findings across attributes, the attributes used in this experiment were largely different from those used in Experiment 1. Again, the attributes covered a variety of personality characteristics, all of which were semantically unrelated to the dimension of cooperation versus conflict (see Appendix A). The list consisted of single attributes rather than attribute pairs (unlike in Experiment 1) to facilitate the later judgments of attribute valence. Participants indicated how characteristic of themselves each attribute was, using a 6-point response scale anchored with totally agree and totally disagree.

Ingroup and outgroup chosen for this study were natural groups familiar to participants. Ingroup was the faculty (or school) of psychology where the participants studied (FPCE-UL). The outgroup was a private institute known as ISPA. It was the first superior school of psychology in Lisbon and enjoys a very positive reputation. The ingroup, FPCE-UL, was founded 18 years later, is part of the University of Lisbon, and, because it is funded by the public, is usually students' first choice when they apply for higher education in psychology. FPCE-UL students often draw comparisons between themselves and ISPA students regarding matters such as academic programs, average grades, their professors' reputation, and the research orientation of the two institutions. Furthermore, they also perceive ISPA students as future competitors when applying for jobs after graduation. Thus, students at FCPE-UL seem to perceive ISPA as a meaningful outgroup and the relationship between these two institutions as competitive.

We manipulated perceived intergroup relationship (cooperation vs. conflict) with a scenario which followed on the next page after the selfratings in the questionnaire. The scenario started as follows: 'The government body Fundação para a Ciência e Tecnologia has announced that it will fund the organization of a major international conference on the topic of Psychology in the $21^{\text {st }}$ century. The application period has now been opened. The best application is the one that ensures the participation of the highest number of renowned researchers. This in turn strongly depends on the social network of the applying institution. Organizing such a conference is a privilege for the applying academic institution and it is also highly beneficial for its students, as it will enhance the visibility of the institution to potential employers and will enable the students to have a privileged contact with eminent international researchers. Both your institution, Faculdade de Psicologia e Ciências da Educacão da Universidade de Lisboa (FPCE-UL), and Instituto 
Superior de Psicologia Aplicada (ISPA) announced that they will be applying'.

Intergroup relationship was manipulated in the last paragraph of the scenario. In the competition condition, the paragraph was as follows: 'Only one institution can win the funding for organizing the conference, namely the one that presents the best list of delegates. Thus, FPCE-UL and ISPA will be competing. Only one of them, but not both, can win the funding. If one wins it, the other will get nothing'.

In the cooperation condition, the paragraph was as follows: "It is possible that two institutions submit a joint application. FPCE-UL and ISPA decided to draw on their joint social networks to present a single list of invited researchers in their application. This cooperation increases their chances of winning the funding compared to the case that they apply individually. If their joint application succeeds, both FPCE-UL and ISPA will get funding'.

On the next pages of the questionnaire, participants judged the outgroup (members of ISPA) and the ingroup (members of FPCE-UL) on the same attribute list as the self. Like in Experiment 1, the outgroup was always judged before the ingroup, and participants were encouraged to rely on their spontaneous and intuitive impressions. In addition, participants judged common ingroup identity (items: 'I consider FPCE-UL and ISPA as a single, large group' and 'I consider FPCE-UL and ISPA as two clearly distinct groups' (reversed-coded), 6-point scales anchored with totally agree and totally disagree, $r=.49$ ) and intergroup similarity (item: 'On the whole, how similar are FPCE-UL and ISPA in your view?', 6-point response scale anchored with very similar and very dissimilar). The order of the two sets of scales (group ratings on the one hand and judgments of common identity and similarity on the other) was counterbalanced across participants.

At end of the questionnaire, participants provided demographic data and were asked the following question as a manipulation check: 'In the situation presented earlier, FPCE-UL and ISPA were: competing-cooperating (Please select the correct option)'. This question allowed us to filter participants that may have misunderstood the scenario or not read it carefully. As already mentioned, only the data of participants who gave the correct answer were analyzed.

We estimated the same multilevel models as in Experiment 1, with the exception that the variable 'attribute valence' denoted idiosyncratic rather than norm-based valence ratings. In addition, we tested whether the effects of the experimental manipulation was due to effects on common ingroup identity or perceived intergroup similarity (a special case of mediated moderation). To this end, in two additional analyses, we entered these two variables as predictors alongside the experimental manipulation into the multilevel models. To the extent that the effects of the manipulation were weaker in these analyses, this would indicate that those variables mediated the effects of conflict. Specifically, in these additional analyses, we tested the following models:

(a) As to common ingroup identity:

Level-1 Model

Outgroup ratings $=\mathrm{P} 0+\mathrm{P} 1 *$ (self-ratings $)+$ $\mathrm{P} 2 *$ (attribute valence) $+\mathrm{E}$

Level-2 Model

$\mathrm{P} 0=\mathrm{B} 00+\mathrm{B} 01 *($ condition $)+\mathrm{B} 02 *($ common identity) $+\mathrm{R} 0$

$\mathrm{P} 1=\mathrm{B} 10+\mathrm{B} 11 *($ condition $)+\mathrm{B} 12 *($ common identity) $+\mathrm{R} 1$

$\mathrm{P} 2=\mathrm{B} 20+\mathrm{R} 2$

(b) As to perceived similarity:

Level-1 Model

Outgroup ratings $=\mathrm{P} 0+\mathrm{P} 1 *$ (self-ratings $)+$ $\mathrm{P} 2 *($ attribute valence $)+\mathrm{E}$

Level-2 Model

$$
\begin{aligned}
& \mathrm{P} 0=\mathrm{B} 00+\mathrm{B} 01 *(\text { condition })+ \\
& \mathrm{B} 02 *(\text { similarity })+\mathrm{R} 0 \\
& \mathrm{P} 1=\mathrm{B} 10+\mathrm{B} 11 *(\text { condition })+ \\
& \mathrm{B} 12 *(\text { similarity })+\mathrm{R} 1 \\
& \mathrm{P} 2=\mathrm{B} 20+\mathrm{R} 2
\end{aligned}
$$

with P0, B00, B10, B20: intercepts; P1, P2, B01, B02, B11, B12: regression weights; and E, R0, $\mathrm{R} 1, \mathrm{R} 2$ : residuals. 
In these analyses, following the recommendations of Hofmann and Gavin (1998), we centered the Level 1 predictors (self-ratings and attribute valence) at their means within each participant and the nondichotomous Level 2 predictors (common ingroup identity and perceived intergroup similarity) at their overall mean.

\section{Results and Discussion}

As predicted, the relation between self- and outgroup ratings depended negatively on the competition versus cooperation manipulation $(B=-0.11, S E=0.05, p=.02)$. Figure 2 illustrates the effect. The effect of self-ratings was slightly positive under cooperation $(B=0.05$, standardized coefficient .06) and negative under competition $(B=-0.06$, standardized coefficient-.07), suggesting positive and negative outgroup projection, respectively.

Like in Experiment 1, we explored the role of ingroup image by entering ingroup ratings as an additional predictor and testing the moderating effect of the manipulation on both the ingroup-outgroup and self-outgroup relation simultaneously. The effect of the manipulation on the self-outgroup relation remained virtually the same as in the initial analysis $(B=-0.09$, $S E=0.05, p=.04)$. Unlike in Experiment 1 , the manipulation had no significant effect on the ingroup-outgroup relation $(B=-0.06, S E=0.07$, $p=.38$ ). Thus, the ingroup image, and hence indirect projection from self to outgroup via ingroup, did not play a role in the effects of the manipulation. This fails to support the model depicted in Figure 1, panel B. The manipulation affected only direct (rather than indirect) projection from self to outgroup.

For the sake of completeness, we tested for ingroup projection, just like in Experiment 1. Again, the self-ingroup relation was positive $(B=0.21, S E=0.03, p<.0001$, standardized coefficient .23) suggesting that ingroup projection did occur. Further analyses (analogous to those in Experiment 1) revealed an unexpected effect of the manipulation on the self-ingroup relation $(B=0.14, S E=0.05, p=.01)$. This suggests that ingroup projection was stronger under competition than cooperation, contrary to the effect of the manipulation on outgroup projection.

Next, we explored whether common ingroup identity and/or perceived intergroup similarity mediated the effects of the manipulation on self-outgroup projection. To this end, as explained in the Method section, we entered each of these two variables as a second predictor into the equation for conflict. In either case, the effect for conflict remained almost the same as in the initial analysis $(B=-0.09, S E=0.05, p=.05$ and $B=-0.11, S E=0.05, p=.02$, respectively). In addition, common ingroup identity, but not perceived intergroup similarity, significantly moderated self-outgroup projection $(B=0.042$, $S E=0.019, p=.03$; and $B=0.038, S E=0.023$, $p=.11)$. Further, $t$-tests revealed that neither common ingroup identity nor perceived intergroup similarity were significantly affected by the manipulation ( $M=3.52$ in the cooperation condition vs. 3.21 in the competition condition, $t=1.39, p=.17$ and $M=2.73$ vs. $2.80, t=0.34$, $p=.73$, respectively).

Thus, common ingroup identity turned out to be another moderator of outgroup projection but did not explain the effects of manipulated intergroup relationship. In other words, recategorization did not seem to play a role in the effects of the manipulation on self-outgroup projection. Moreover, no significant evidence for a role of perceived similarity in outgroup projection was obtained.

In sum, Experiment 2 replicated the finding from Experiment 1 that perceived intergroup cooperation versus competition leads to more positive outgroup projection. Overall, outgroup projection was less positive in this than in the preceding experiment, and was even negative in the competition condition. A possible reason for this difference between the experiments is that this experiment referred to real-life (rather than hypothetical) groups and that participants were likely to view the intergroup relationship as competitive in real life. Thus, especially the competition condition of this experiment (though still hypothetical) may have been personally more relevant and more plausible than the competition condition in Experiment 1. These factors in turn may be preconditions 
for negative outgroup projection (as argued by Mullen, Dovidio, Johnson \& Copper, 1992; Riketta, 2005; Spears \& Manstead, 1990). Further, like in Experiment 1, cooperation versus competition seemed to affect direct (self-to-outgroup) rather than only indirect (self-to-ingroup-tooutgroup) projection. Finally, the effect of the experimental manipulation could not be reduced to recategorization or perceived intergroup similarity.

\section{General discussion}

The two experiments, one with fictitious groups and one with natural groups, consistently show that perceived intergroup cooperation versus competition leads to stronger projection of self-attributes to outgroups. This supports our main hypothesis that perceived intergroup relationship moderates outgroup projection. Our studies extend previous correlational research on this moderator hypothesis (Riketta, 2005) by enabling causal conclusions. Our manipulation of perceived intergroup relationship ensured that this variable was a cause, rather than consequence, of projection. Moreover, by having participants judge their self-image before the ingroup-outgroup categorization was made salient, we ensured that the effects of the manipulation pertained to projection from self to outgroup rather than to the reverse process (internalization of outgroup attributes into the self-image, as a special case of self-stereotyping; cf. Turner, 1987). Thus, our studies are the first to demonstrate that perceived intergroup relationship influences outgroup projection.

A second goal of this research was to test whether the effect of perceived intergroup relationship pertained to indirect projection from self to outgroup via ingroup rather than to direct projection from self to outgroup. The former possibility is suggested by the self-anchoring/ differentiation model (Cadinu \& Rothbart, 1996). Although perceived intergroup relationship affected ingroup-outgroup projection in one of the two experiments (Experiment 1), perceived intergroup relationship affected self-outgroup projection independently of this effect in both experiments. Thus, perceived intergroup relationship seems to influence direct projection from self and outgroup, independently from the ingroup image. This finding is important more in general because it attests to the very existence of direct projection from self to outgroup, a notion questioned by several researchers (e.g. Cadinu \& Rothbart, 1996; Robbins \& Krueger, 2005) but postulated by cognitive consistency theories (Greenwald et al., 2002; Heider, 1958).

A third goal of this research was to explore whether the effects of the manipulation could be reduced to recategorization (i.e. viewing in- and outgroup as members of a single group, resulting in common ingroup identity; cf. Gaertner et al., 1993) or perceived intergroup similarity (cf. Ames, 2004a,b). Controlling for these variables did not markedly change the effects of the manipulation on the self-outgroup relation. Thus, the effects of manipulated conflict seem to be genuine rather than a special case of ingroup-outgroup recategorization or perceived similarity between ingroup and outgroup. This distinguishes our research from research on recategorization (e.g. Gaertner et al., 1993) and studies on the role of perceived similarity in projection (Ames, 2004a,b; also Jones, 2004). Note that we looked at ingroup-outgroup similarity whereas Ames and Jones looked at self-target similarity. Thus, the findings do not rule out that perceived self-outgroup similarity mediates the effects of the manipulation.

Consistent with previous research, we also found evidence of projection to the ingroup in both experiments (e.g. see Otten, 2002; Robbins \& Krueger, 2005). More important, the intergroup relationship manipulation did not affect ingroup projection in Experiment 1 and changed it in a manner different from outgroup projection in Experiment 2. This dissociation suggests that the effects we expected and found for outgroup projection are specific to outgroups and do not pertain to a general tendency to project to any group.

Our studies point to several avenues for further research. Because only one of our experiments used natural groups, further replications with natural groups are desirable. In doing so, one could explore the generality across groups and could try other manipulations of 
intergroup relationship (e.g. real competition versus cooperation between the groups on laboratory tasks). Morever, given the elusiveness of outgroup projection in previous research, additional moderators apart from perceived intergroup relationship may exist. Thus, further research on the boundary conditions of outgroup projection seems worthwhile. For example, one could test whether the effect of perceived intergroup relationship on outgroup projection is stronger for people higher in the need for cognitive balance or structure (Greenwald et al., 2002; Heider, 1958), or for whom the intergroup situation is personally more important (Riketta, 2005; Spears \& Manstead, 1990). Finally, future research may address the role of outgroup projection in stereotype formation and intergroup behavior. In particular, outgroup projection may be one of the mechanisms through which intergroup contact shapes stereotypes of the outgroup (cf. Pettigrew, 1998; Sherif et al., 1961), especially on dimensions unrelated to the content domain of the intergroup contact.

Now that the existence of outgroup projection has been demonstrated, we believe that this phenomenon deserves more attention in research than it has hitherto received. The evidence accrued so far suggests that outgroup projection is an intriguing but often overlooked process by which people make sense of the social world.

\section{Acknowledgments}

We are grateful to several anonymous reviewers for comments on previous versions of this paper and Luis Curral for supporting the data collection for Experiment 2.

\section{References}

Aiken, L. S., \& West, S. G. (1991). Multiple regression: Testing and interpreting interactions. Thousand Oaks, CA: Sage.

Alexander, M.G., Brewer, M.B., \& Herrmann, R.K. (1999). Images and affect: A functional analysis of outgroup stereotypes. Journal of Personality and Social Psychology, 77, 78-93.
Ames, D. R. (2004a). Inside the mind reader's tool kit: Projection and stereotyping in mental state inference. Journal of Personality and Social Psychology, 87, 340-353.

Ames, D.R. (2004b). Strategies for social inference: A similarity contingency model of projection and stereotyping in attribute prevalence estimates. Journal of Personality and Social Psychology, 87, 573-585.

Baron, R. M., \& Kenny, D. A. (1986). The moderator-mediator variable distinction in social psychological research: Conceptual, strategic, and statistical considerations. Journal of Personality and Social Psychology, 51, 1173-1182.

Cadinu, M.R., \& Rothbart, M. (1996). Selfanchoring and differentiation processes in the minimal group paradigm. Journal of Personality and Social Psychology, 70, 661-677.

Clement, R.W., \& Krueger, J. (2002). Social categorization moderates social projection. Journal of Experimental Social Psychology, 38, 219-233.

Gaertner, S.L., Dovidio, J. F., Anastasio, P. A., Bachman, B. A., \& Rust, M. C. (1993). The common ingroup identity model: Recategorization and the reduction of intergroup bias. In W. Stroebe \& M. Hewstone (Eds.), European review of social psychology (Vol. 4, pp. 1-26). London: Wiley.

Gramzow, R. H., Gaertner, L., \& Sedikides, C. (2001). Memory for ingroup and outgroup information in a minimal group context. Journal of Personality and Social Psychology, 80, 188-205.

Greenwald, A. G., Banaji, M. R., Rudman, L. A., Farnham, S. D., Nosek, B. A., \& Mellott, D. S. (2002). A unified theory of implicit attitudes, stereotypes, self-esteem, and self-concept. Psychological Review, 109, 3-25.

Hager, W., \& Hasselhorn, M. (Eds.) (1994). Handbuch deutschsprachiger Wortnormen

[Handbook of German word norms]. Göttingen: Hogrefe.

Heider, F. (1958). The psychology of interpersonal relations. New York: Wiley.

Hewstone, M., Rubin, M., \& Willis, H. (2002). Intergroup bias. Annual Review of Psychology, 53, 575-604.

Hofmann, D. A., \& Gavin, M. B. (1998). Centering decisions in hierarchical linear models: Implications for research in organizations. Journal of Management, 24, 623-641. 
Jones, P. E. (2004). False consensus in social context: Differential projection and perceived social distance. British Journal of Social Psychology, 43, 417-429.

Katz, D., \& Allport, F. (1931). Students' attitudes. Syracuse, NY: Craftsman.

Kelley, H. H., \& Thibaut, J. W. (1978). Interpersonal relations: A theory of interdependence. New York: Wiley.

Krueger, J. (1998). On the perception of social consensus. Advances in Experimental Social Pschology, 30, 163-240.

Krueger, J. (2000). The projective perception of the social world. In J. Suls \& L. Wheeler (Eds.), Handbook of social comparison (pp. 323-351). New York: Kluwer.

Krueger, J., \& Zeiger, J. S. (1993). Social categorization and the truly false consensus effect. Journal of Personality and Social Psychology, 65, 670-680.

Mullen, B., Atkins, J. L., Champion, D. S., Edwards, C., Hardy, D., Story, J. E. et al. (1985). The false consensus effect: A meta-analysis of 115 hypothesis tests. Journal of Experimental Social Psychology, 21, 262-283

Mullen, B., Dovidio, J. F., Johnson, C., \& Copper, C. (1992). Ingroup-outgroup differences in social projection. Journal of Experimental Social Psychology, 28, 422-440.

Muller, D., Judd, C. M., \& Yzerbyt, V. Y. (2005). When moderation is mediated and mediation is moderated. Journal of Personality and Social Psychology, 89, 852-863.

Otten, S. (2002) 'Me' and 'us' or 'us' and 'them'? The self as heuristic for defining novel ingroups. European Review of Social Psychology, 13, 1-33.

Otten, S., \& Wentura, D. (2001). Self-anchoring and ingroup favoritism: An individual-profiles analysis. Journal of Experimental Social Psychology, 37, 1049-1071.

Pettigrew, T. F. (1998). Intergroup contact theory. Annual Review of Psychology, 49, 65-85.

Raudenbush, S. W., \& Bryk, A. S. (2002). Hierarchical linear models (2nd ed.). Thousand Oaks, CA: Sage.

Raudenbush, S. W., Bryk, T., \& Congdon, R. (2004). HLM 6 hierarchical linear and nonlinear modeling (computer program). Lincolnwood, IL: Scientific Software International, Inc.

Riketta, M. (2005). Cognitive differentiation between self, ingroup, and outgroup: The roles of identification and perceived intergroup conflict. European Journal of Social Psychology, 35, 97-106.
Riketta, M. (2006). Projection of self-attributes to outgroups. In A. B. Prescott (Ed.), The concept of self in psychology (pp. 215-241). Hauppauge, NY: Nova.

Robbins, J.M., \& Krueger, J. (2005). Social projection to ingroups and outgroups. Personality and Social Psychology Review, 9, 32-47.

Sherif, M., Harvey, O. J., White, B. J., Hood, W. R., \& Sherif, C. W. (1961). Intergroup conflict and cooperation: The robbers cave experiment. Norman, OK: University of Oklahoma Book Exchange.

Sherman, S. J., Chassin, L., Clark, C. P., \& Agostinelli, G. (1984). The role of evaluation and similarity principles in the false consensus effect. Journal of Personality and Social Psychology, 47, 1244-1262.

Smith, E. R., \& Henry, S. (1996). An ingroup becomes part of the self: Response time evidence. Personality and Social Psychology Bulletin, 22, 635-642.

Spears, R., \& Manstead, A. S. R. (1990). Consensus estimation in social context. European Review of Social Psychology, 1, 81-109.

Turner, J. C. (1987). A self-categorization theory. In J. C. Turner, M. A. Hogg, P. J. Oakes, S. D. Reicher, \& M. S. Wetherell, (Eds.), Rediscovering the social group (pp. 42-67). Oxford, UK: Blackwell.

Paper received 21 February 2006; revised version accepted 16 May 2007

\section{Biographical notes}

MICHAEL RIKETTA is lecturer in work and organizational psychology at Aston Business School, Aston University, Birmingham. He has received first degrees in socioeconomics (University of Augsburg, Germany) and psychology (University of Eichstätt, Germany) and a doctor's degree in psychology (University of Mannheim, Germany). He has worked as researcher and lecturer at the universities of Eichstätt, Mannheim and Tübingen, Germany. His current research areas are (a) identification and commitment in organizations, (b) social projection and (c) self-esteem.

CLAUDIA SACRAMENTO is a doctoral researcher in work and organizational psychology at Aston Business School, Aston University, Birmingham. Her current research interests concern individual and team creativity, team processes, the impact of stressors on teams, and intergroup relations. 


\section{Appendix A: Adjectives for self- and group ratings}

\section{Experiment 1}

not sociable - sociable

sensitive - not sensitive trustworthy - not trustworthy intelligent - unintelligent humorous - having no sense of humor

narrow-minded - open-minded tidy - untidy honest - dishonest conventional - individualistic athletic - unathletic decent - indecent introverted - extraverted

unreliable - reliable rational - irrational opportunistic - principled attractive - unattractive nervous - calm

Notes: The adjective list in Experiment 1 included three additional attributes, which were semantically related to the dimension of conflict versus cooperation (friendly - unfriendly, quarrelsome - peaceful, uncooperative-cooperative). Because the judgments on these attributes may reflect direct inferences from the scenario rather than projection from the self, they were not included in the present analyses. The adjectives for Experiment 2 were selected to represent four of the Big Five personality traits (extraversion, neuroticism, conscientiousness, and openness to experience; four adjectives each). The remaining Big Five trait, agreeableness, was omitted from the study because it is semantically related to the dimension of conflict versus cooperation.

\section{Appendix B: Regression Equations Estimated in the Multilevel Analyses}

$\mathrm{S}$, O, and I: self-, outgroup, and ingroup ratings, respectively. C: condition. V: attribute valence. 2 . CI: common ingroup identity. SI: perceived intergroup similarity. Equations (a) refer to the analysis with valence as control variable (as reported in the text) and equations (b) refer to the analysis without valence as control variable.

\section{Experiment 1}

Test for the moderating effect of conflict on outgroup projection

Without ingroup ratings:

(a) $\mathrm{O}=2.95+0.07 * \mathrm{C}+(0.39-0.09 * \mathrm{C}) * \mathrm{~S}+1.26 * \mathrm{~V}$

(b) $\mathrm{O}=3.34+0.10 * \mathrm{C}+(0.72-0.12 * \mathrm{C}) * \mathrm{~S}$

With ingroup ratings:
(a) $\mathrm{O}=3.26+0.10 * \mathrm{C}+(0.07-0.04 * \mathrm{C}) * \mathrm{~S}+(0.84$ $-0.08 * \mathrm{C}) * \mathrm{I}+0.21 * \mathrm{~V}$
(b) $\mathrm{O}=3.34+0.10 * \mathrm{C}+(0.07-0.04 * \mathrm{C}) * \mathrm{~S}+(0.84$ $-0.07 * \mathrm{C}) * \mathrm{I}$

Test for ingroup projection

Without condition:
(a) $\mathrm{I}=3.61+0.19 * \mathrm{~S}+1.96 * \mathrm{~V}$
(b) $\mathrm{I}=3.61+0.51 * \mathrm{~S}$

With condition:
(a) $\mathrm{I}=3.69-0.02 * \mathrm{C}+(0.42-0.05 * \mathrm{C}) * \mathrm{~S}+1.96 * \mathrm{~V}$
(b) $\mathrm{I}=3.68-0.02 * \mathrm{C}+(0.80-0.06 * \mathrm{C}) * \mathrm{~S}$

Experiment 2

Test for the moderating effect of conflict on outgroup projection

Without ingroup ratings:

(a) $\mathrm{O}=3.63-0.08 * \mathrm{C}+(0.05-0.11 * \mathrm{C}) * \mathrm{~S}+0.18 * \mathrm{~V}$

(b) $\mathrm{O}=3.63-0.08 * \mathrm{C}+(0.20-0.14 * \mathrm{C}) * \mathrm{~S}$

With ingroup ratings:
(a) $\mathrm{O}=3.63-0.08 * \mathrm{C}+(0.04-0.09 * \mathrm{C}) * \mathrm{~S}+(0.14$ $-0.06 * \mathrm{C}) * \mathrm{I}+0.14 * \mathrm{~V}$
(b) $\mathrm{O}=3.63-0.08 * \mathrm{C}+(0.12-0.11 * \mathrm{C}) * \mathrm{~S}+(0.20$ $-0.05 * \mathrm{C}) * \mathrm{I}$

Test for ingroup projection

Without condition:
(a) $\mathrm{I}=3.50+0.21 * \mathrm{~S}+0.28 * \mathrm{~V}$
(b) $\mathrm{I}=3.50+0.41 * \mathrm{~S}$

With condition:
(a) $\mathrm{I}=3.53-0.06 * \mathrm{C}+(0.14+0.14 * \mathrm{C}) * \mathrm{~S}+0.28 * \mathrm{~V}$
(b) $\mathrm{I}=3.53-0.06 * \mathrm{C}+(0.35+0.11 * \mathrm{C}) * \mathrm{~S}$ 
Test for the mediating role of common group identity

(a) $\mathrm{O}=3.64-0.10 * \mathrm{C}-0.06 * \mathrm{CI}+(0.04-0.09 * \mathrm{C}+$ $0.04 * \mathrm{CI}) * \mathrm{~S}+0.18 * \mathrm{~V}$

(b) $\mathrm{O}=3.64-0.10 * \mathrm{C}-0.06 * \mathrm{CI}+(0.19-0.12 * \mathrm{C}+$ $0.05 * \mathrm{CI}) * \mathrm{~S}$
Test for the mediating role of perceived intergroup similarity

(a) $\mathrm{O}=3.62-0.07 * \mathrm{C}-0.07 * \mathrm{SI}+(0.05-0.11 * \mathrm{C}+$ $0.04 * \mathrm{SI}) * \mathrm{~S}+0.18 * \mathrm{~V}$

(b) $\mathrm{O}=3.62-0.07 * \mathrm{C}-0.07 * \mathrm{SI}+(0.20-0.14 * \mathrm{C}+$ $0.05 * \mathrm{SI}) * \mathrm{~S}$ 